1.

\title{
Facilitating Diversity-Centred Adult Computing Education
}

Danielle Johnstone \& Caroline Pelletier

Transactions of the Digital Games Research Association August 2018, Vol 4 No 1, pp 1-30 ISSN 2328-9422

(C) The text of this work is licensed under a Creative Commons Attribution -- NonCommercial --NonDerivative 4.0 License (http://creativecommons.org/licenses/by-nc-nd/ 2.5/).

IMAGES: All images appearing in this work are property of the respective copyright owners, and are not released into the Creative Commons. The respective owners reserve all rights.

\section{ABSTRACT}

This article draws from a dissertation composed of ethnographical study on the work of codebar London, a chapter of an organisation working to diversify the tech work force by offering free programming workshops to under-represented people. It delves into the role played by codebar's organisers, considering how the problem of gender, ethnic and sexual under- 
representation in technology work leads to codebar's particular effort to solve it. In exploring links between the organisers' work and existing theories about empowering pedagogy, it addresses the question: How is diversity practiced educationally?

Keywords

Diversity, education, pedagogy, feminism, programming

\section{INTRODUCTION}

Much of the consideration of intersections between gaming and identity politics (including gender, race and sexuality) has focused on representation and play-what games contain and who plays them. This is particularly salient because of the ways that people-children in particular-perform their identity through the games they play and how they speak about them (Pelletier 2008). But another concern scholars have considered when thinking about gaming and identity is who is makinggames. Indeed, this underlies some of the considerations of game play and game development, because there is a sense that ethnic, gender and sexual homogeneity in the design and use of games could be related to homogeneity in the ranks of those who develop them. In fact, questions about the identity of developers are ubiquitous throughout the study of tech work.A question that seems immediately connected to technology and technology work in the media and public consciousness seems to be: What can be done to solve tech's diversity problem? From international news-pieces on the latest sexual harassment scandal (Bosa, Balakrishnan, and Haselton 2017) to public company strategies for addressing underrepresentation and lack of inclusivity in the workforce (Google 2017), the fact that tech workers are predominantly white, straight, cis-gendered men and the concerns about effects this could have on the technologies themselves never seem to be far from any mention of the tech industry. That there is a problem seems indisputable; how it has come about is, in many ways, 
contested; and what is to be done about it is not entirely obvious. Yet, there are people doing things about this. For one, there are people working hard to make a place in tech for potential workers who identify as women, LGBTQ and/or of an ethnic minority.

One place you will find such people is in the ranks of volunteers who run the London chapter of an organisation called codebar. codebar is a non-profit composed of local chapters around the world. Each of these chapters facilitates workshops in office space donated by tech companies, where professional programmers volunteer to coach adult learners in the early stages of learning to code. The London (or, more specifically, the centralLondon) chapter was the first to be founded, and organisers running this chapter are also tasked with managing the organisation as a whole-from maintaining the website, to providing guidance and finance for new and smaller chapters, to writing manuals for coaches, students and sponsors. The organisers of this chapter are, for all intents and purposes, the creators and defenders of codebar's mission and model. They have crafted an approach to education that is uniquely designed for the purpose of educating the people they aim to serve.

So why study codebar-what does researching it contribute to debates about diversity and gender in game culture? We have two main reasons, in this article. First, we aim to build on the work that has already been done on diversity initiatives in the games sector, notably the work of Alison Harvey, Stephanie Fisher and Tamara Shepherd (Harvey and Fisher 2015) (Harvey and Shepherd 2017) (Harvey and Fisher 2013) (Fisher and Harvey 2013). This work makes a strong case for such initiatives, whilst also highlighting the tensions they sustain, notably between aims and process. Fisher and Harvey (2013), for instance, highlight the difficulties faced by organisers of interventions for 'inclusivity' and 'diversity' who aim to increase the representation of women in the games sector, but who encounter resistance, notably from presumed beneficiaries of 'diversity' work, because of the terms on which inclusion is offered. Interventions which presume a 
deficit in intended beneficiaries — notably lack of understanding, education and skill—can reinscribe exclusion, rather than remedy it, and consequently, provoke a rejection or questioning of the intervention's design. Fisher and Harvey's analysis points both to the fraught politics of 'reaching out' to under-represented groups in the tech workforce, and the emotional labour involved in navigating these coherently. This article focuses specifically on this: on the pedagogy of an intervention, and on how diversity is practiced in the way 'inclusion' is offered. We also examine the difficulties this pedagogy created for organisers, as well as the emotional labour required to respond to them.

Our second, related reason for analysing codebar's activities is to develop a better understanding of what a feminist and critical pedagogy might look like in the tech sector. In education literature, there are extensive debates about how equality can be produced in acts of teaching and learning. This strand of work is notably inspired by the work of Paulo Freire, but also more recently by feminist scholarship, such as bell hooks' work, which attends to intersectionality. We draw on this to interpret codebar's pedagogy, and thereby, explore how educational interventions in the tech sector, which aim at achieving greater 'diversity', might be understood in the politicised terms of empowerment and emancipation. Our aim here is to treat 'diversity' work as essentially political. In this, we align ourselves again with Harvey et al.'s efforts to conceptualise diversity as pertaining to the exercise of power, the inscription of inclusion and exclusion, rather than imbalances in an apolitical meritocracy.

This article draws from a larger dissertation of ethnographical research on codebar's approach to education. It focuses on the work of being a codebar organiser and how this role compares to the facilitation of liberatory learning described in bell hooks' intersectional feminist pedagogy. 


\section{BACKGROUND}

The issue of diversity (or the lack of it) in the tech sector has become a lightning rod for media attention. And, indeed, if we consider statistics about tech hiring, the homogeneity of the tech sector is concerning-Stack Overflow’s 2017 global developer survey, for instance, noted that, of their respondents, over $74 \%$ identified as white or European, and over $88 \%$ identified as male (excluding those who identified solely as transgender) (Stack Overflow 2017). It may be that some of the surprise about these statistics comes from the misplaced assumption that technologies and cyberspaces are inherently more free, open and even progressive-created recently and therefore without the long histories of prejudice and subjugation that have constructed social categories and power structures around race and gender. These presumptions about technology — most of which have been refuted by scholarship on prejudice and cybertyping within technologies and virtual worlds (Nakamura 2013)_-are connected to the questions we ask about tech work. Given that the option of industrial programming as a career is relatively new, the industry established in a world where stereotypes about the abilities and roles of women and ethnic minorities have been seriously challenged, why is tech a white man's world?

Scholars have written about attributes of tech work that undermine the diversity of the workforce, including considering how the cultural identity of tech work can alienate underrepresented people. Mia Consalvo, in a chapter on women game developers in the book Beyond Barbie and Mortal Kombat (Consalvo 2008), highlights how two particular elements of game industry culture-_"passion” and "crunch time”-undermine women's desire to enter or remain in the gaming workforce. She suggests that the prevailing culture demanding long working hours (without overtime pay) and hiring based on passion is not gender-directed, but has a gendered effect. The women Consalvo spoke to clearly felt conflicted between their love of gaming, their career ambitions, the realities of their home life, and an overall 
sense of unfairness. Indeed, unfairness appears to be at the centre of the reasons tech workers of underrepresented identity leave tech employment (or, arguably, choose not to enter it). A survey on tech leavers by the Kapor Center showed how stereotyping and humiliation, being passed over for promotion, and sexual harassment were disproportionately experienced by tech workers who identified as women, LGBTQ and/or of an ethnic minority (Scott, Klein and Onovakpuri 2017).

While some scholars point to the nature and culture of tech work as the source of tech's diversity problem, others suggest it is more to do with access to career entry-that it is an educational "pipeline” problem. Zarrett and Malanchuk argue that there is a gender and race-based "leaky pipeline" to IT work-that statistics show how gender and race are indicators of how likely a person is to consider a path to advanced computing work, to pursue such a path, and to continue on it (Zarrett and Malanchuk 2005). This corresponds with writings by Manju Ahuja, who explores how adult women's decisions to enter, persist and advance in tech careers are affected by structural and cultural influences (Ahuja 2002). Adya and Kaiser build on this to posit that career genderisation happens early in adolescence and that girls' choices about whether to pursue IT can be traced to specific social influences_- “gender stereotyping, role models, peers, media, and parents" —and structural influences_- "manifested in the institutional support available, such as teachers and counselors, access to technology, and same-sex versus coeducational schools” (Adya and Kaiser 2005).

At the same time, tech education is arguably becoming increasingly accessible due to the significant growth in the number of methods available for people to learn programming. These range from traditional computer science degrees, to individual MOOCs hosted on mainstream websites like Coursera, to virtualised versions of university modules (like the famed Harvard/Yale introductory computer science CS50 course), to language learning tools (like guided coding environments such as 
Code Academy or Scratch). And, in the midst of this, there are considerations of how computing education can be re-shaped to qualify a more diverse population of programmers. Vivian Annette Lagesen, in her exploration of attempts by the Norwegian University of Science and Technology to recruit more women to study computer science, argues that a "direct effort to increase the relative number of women” learning computer science is the most important and effective strategy, having symbolic as well as practical effects, as women become more present in the techlearning space (Lagesen 2007, 67). On the other hand, a study on introductory programming education by Rubio et al. suggests that rather than waiting for a change in the symbolism around computing, pedagogical approaches in teaching computer science should take into account the different perceptions men and women have about programming to equalise outcomes (Rubio et al. 2015). But uncertainties remain about what a truly inclusive educational experience for underrepresented programmers really looks like. These concerns are raised, in part, by Fisher and Harvey (2013), whose work addresses the inherent tensions in efforts in the games sector in "offering” inclusion in ways that may seem patrimonial or presumptive of disadvantage. As a result, the lingering question is how can educational experiences that are inclusive and empowering in nature as well as goals be (or are being) constructed and pursued?

This study considers that question, exploring how the efforts of a team of organisers work to create a proactive, productive and inclusive learning experience for prospective career changers of marginalized identities who are starting to learn programming. It explores what a grassroots, diversity-centred programming education approach involves, and what the set of volunteer organisers do to help create and maintain it. In particular, it asks how the workings of the organisation resemble existing theory about empowering and inclusive modes of learning. 


\section{THEORETICAL FRAMING}

To approach an analysis of how codebar organisers enact education to empower tech learners, it was useful to consider what existing models for empowering education look like in general. Thus, the theoretical framings of this study came from models of anti-oppressive learning, in particular those of bell hooks.

bell hooks' theory of transgressive learning provided a useful set of concepts with which to understand codebar's functions. hooks' theory draws from existing models of emancipatory education - those that consider ideal learning as rooted in social justice and "formed in solidarity with the interests of the least powerful in society” (Thompson 2000). Paolo Freire-arguably the founding theorist of emancipatory pedagogies — was a particular inspiration to hooks. He posits that oppression is a learned state, reiterated by discriminatory and uneven schooling systems which rely on didactic "banking” whereby an expert instructor deposits knowledge within passive students (Freire 1970). This oppression must be un-learned by a process of growing self-awareness on the part of both the oppressor and the oppressed, and through sustained dialogue. A key scholar of black feminist issues, hooks went beyond Freire's class-focused model (and those of some Freire-inspired feminist models) to consider a range of intersecting marginalised identities, including gender, race and sexuality. She describes a pedagogy that transgresses the traditional race, class and gender limitations of "banking" education models, and engages in teaching that critiques oppression and gives voice to the oppressed.

In Teaching to Transgress(hooks 1994), bell hooks explains her own autobiographical connection with Freire's Pedagogy of the Oppressed. As a black woman, her learning experiences were characterised by the oppression of a misogynistic white supremacy weaved into the schooling system, which resulted in continued anxieties about education in her role as instructor. Her 
encounter with Freire was liberating in itself_-it provided another vision for what education could be, for learning and teaching as radical acts of transgression. Of especial interest for this study is hooks' guidance for the enactingof pedagogical theory in the liberating classroom - the transgressive praxis. In particular, hooks focuses on the role of the instructor in establishing and enacting emancipatory pedagogies. The praxis she describes involves the instructor ceding some of the more toxic elements of authority to collaborate with students in a participatory and critical mode of learning. If we accept Shrewsbury's claim that the three central concepts of feminist pedagogy are "community, empowerment and leadership” (Shrewsbury 1993, 10), we can conceive of how hooks' particular intersectional and transgressive brand of this pedagogy fits into the tradition, because it frames transgressive education as the crafting of a learning community through instructor's taking leading responsibility to distribute authority and empower students.

hooks explains that, to create an effective collaborative learning community, the instructor must be willing to forgo the "exercise of power and authority within their mini-kingdom, the classroom" (p.17) in favor of a more democratic mode of classroom engagement that prioritises dialogue and allows for individual non-conformity. This comes from a conception of instructorleadership as responsibility "not merely to share information but to share in the intellectual and spiritual growth of our students" (p.13). hooks recognizes that this is a demanding and even intimidating prospect for an instructor - that even the act of shifting the instructor's position from behind a desk to within the learning body and conversant with them seems unsafe, and that the unwillingness to engage in transgressive teaching that allows voice to a diverse student body often stems from the fear that cultural diversity will "replace one dictatorship of knowing with another” (p.32). Yet hooks continues to recognize the student's right to agency in learning, and the instructor's responsibility to respect and encourage this. 
hooks also recognizes that learners' empowerment comes with its own responsibilities — she points out that "making the classroom a democratic setting where everyone feels a responsibility to contribute is a central goal of transformative pedagogy” (p.38). In explaining how this responsibility to contribute is to be fostered in learners, hooks proposes educational practice that gives value to student experience, in contrast to the "banking”, instructorauthoritative education model that Freire critiques. This means two key things. First of all, education must be relevant to the lives of the learners-learning that is shaped by the experiences, desires and assumptions of the instructor without student input will not do this. Secondly, students must be treated as having equal value, within the paradigm of recognising how society may shape and confine the classroom for those of different identities. hooks makes clear that this equalising of students can prevent the feared consequences of experience-acknowledging education - that it will essentialise social conditions and exclude other forms of knowledge. hooks explains how an activity that allows all students to reflect on and share their experiences "makes the classroom a place where experience is valued... [and] students seem less inclined to make the telling of experience that site where they compete for voice” (p.84).

The reconfiguring of power in the learning environment ultimately aims towards a "community of learning", but hooks is clear that "sharing" does not always result in collaborating or connecting. She points to histories of race and gender in the United States, where the shared experience of gender oppression "did not mediate relations between white mistresses and black slave women” (p.97). In fact, the act of community-building can often place a larger burden upon the more marginalised members, which undermines the collaboration itself. For hooks, it is no coincidence that the most effective multi-cultural and multi-racial collaborations within women's studies tend to occur when women of color are not "tasked” with explaining race and privilege to their white collaborators. According to her model, a liberating educational experience must not place the burden of 
consciousness-building and communal understanding on the oppressed, but must give them opportunity and responsibility to participate.

Summarizing hooks' theory, the role of the instructor in transgressive learning can be said to be characterised by three key features:

1. The establishment of a vision of inclusion, which necessarily involves more distributed modes of authority;

2. The necessary experience of vulnerability as a result of surrendering authority and defending student/participant humanity; and

3. The intentional empowerment of students or participants as part of the distribution of authority and recognition of humanity.

This article uses these three factors to address our key question-How is diversity practiced educationally? - through exploring how codebar organisers practice some of the responsibilities of the instructor within the learning model.

\section{METHODOLOGY}

When approaching designing a research methodology for investigating codebar, it became clear that there would be a deep entangling of the organisation's own politics and considerations of power, and the way it should be studied. It became evident early on that there was a strong parallel between the concerns of codebar as an organisation and our own concerns as researchers. To fully examine the work codebar was doing to contest oppressive social constructions of power, gender, ethnicity, sexuality and representation, we wanted to craft a research methodology that challenged the way these forces have traditionally dominated academia. One key form of scholarship 
that has done this is feminist methodology (particularly that feminist methodology developed by LGBTQ people and people of color who challenge other systems of oppression that intersect with gender, including race). This became the cornerstone of our research approach. In particular, we were interested in aspects of feminist methodology which challenge oversimplified examination and elitist distance, "exposing the cultural biases embedded in the game of research” (O’Leary 2013, p.146). As a result, we selected participatory ethnographical methods that required working alongside people in order to understand and recognise perspective.

With the goal of exploring codebar's educational approach, we used three means of data collection: document analysis, interviews and observation. The dissertation, as a whole, took an exploratory approach to investigating codebar's entire organisational approach to education. One aspect of this was the role of organisers, on which this article focuses. Interviews with organisers (one focus group interview with five organisers, and one individual interview with an organiser who was not part of the focus group) gave particular insight into the role and into the way the organising team works. Individual interviews with a student and three coaches allowed us to explore how the organiser role affected coach and student experiences, as well as how participants perceived organisers and the organisation. Web documents from codebar's website (including web-published manuals) gave us a picture of how organisers present the organisation and its work to the public. Finally, observations of two workshops allowed us to see how the codebar pedagogy manifested in the learning space and ways it was facilitated and moderated by the organisers present.

Combining these various sources of data allowed us to examine "the interplay between informal, interpersonal networks and the formal, official social structures” (Millman and Kanter 1987, 32). As a result, the approach to data analysis focused on creating a "thick" description by looking at the data in holistic, contextual 
and discursive ways (Geertz 1973). To achieve a thick description from the data, we determined that we should not only extract from it the themes, structures and experiences the participants explicitly expressed, but also consider their reasons for framing these things in particular ways, and how the different accounts linked and contested. With this in mind, the data analysis combined approaches from thematic analysis (Braun, V. and Clarke 2006) and frame analysis (which, in itself, incorporates elements of discourse analysis) (Johnston 1995).

\section{FINDINGS}

The data collected reflected that codebar organisers played a key facilitating role in manifesting a transgressive feminist pedagogy in the organisation's educational offerings. While organisers did not take on the role of actual instruction (which is conducted by coaches), they did assume responsibilities and characteristics that hooks' model associates with the instructor, particularly in establishing and defending the learning and teaching model used in the workshop.

Table 1: An overview of the codebar structure

\begin{tabular}{|l|l|}
\hline The workshop & $\begin{array}{l}\text { The main codebar offering. Eligible students are matched with coaches (one coach to one or two students) to } \\
\text { receive guidance and tutelage on the introductory computing subject of their choice (typically a particular } \\
\text { programming language). Student-coach groups can follow a tutorial or work on a project. A typical workshop } \\
\text { follows a schedule of: coaches and students registering online, coaches and students arriving and signing in at } \\
\text { the host workspace, participants sharing a meal, organisers matching student groups and coaches volunteering } \\
\text { for a student/group each, and 2 hours of coaching. }\end{array}$ \\
\hline $\begin{array}{l}\text { The } \\
\text { Organizers }\end{array}$ & $\begin{array}{l}\text { The main leadership body of codebar, made up of volunteers. Each local chapter has a group of organisers } \\
\text { charged with planning and facilitating workshops. This includes reaching out to sponsor companies, who } \\
\text { provide workshop space, wifi access, and food and beverages. The organisers for the Central London chapter } \\
\text { also serve as "admin organisers" for the organisation as a whole. }\end{array}$ \\
\hline The Sponsors & $\begin{array}{l}\text { Companies that donate money or host workshops. Hosting involves providing space, wifi access, and food and } \\
\text { beverages. The workshop itself is run by the organisers. }\end{array}$ \\
\hline The Coaches & $\begin{array}{l}\text { Professional developers who volunteer to teach at codebar workshops. They do not necessarily come from a } \\
\text { coaching background, but teach from the perspective of their professional experiences. }\end{array}$ \\
\hline The Students & $\begin{array}{l}\text { Potential programmers at the early stages of learning to code. To attend a codebar workshop as a student, you } \\
\text { must identify as belonging to a social group that is underrepresented in tech - as being a women, of an ethnic } \\
\text { minority and/or LGBTQ. }\end{array}$ \\
\hline
\end{tabular}




\section{Organisers Articulating a Vision of Inclusion}

"codebar is a non-profit initiative that facilitates the growth of a diverse tech community by running regular programming workshops.” For many, this is their first encounter with codebar-a banner across the homepage of the organisation's website, codebar.io. The bright text floats over the top of an image of people huddled around laptops in a vibrant workspace filled with colourful posters and bike racks. This is the official face of codebar, and everyone involved with the organisation will have visited it. Not only is it a space packed with information-from mission statements to personal accounts to lists of local chapters and scheduled events-it is also the gateway to participation. It is here that interested parties come to learn more, here that potential sponsors find contact information for organisers and directions on how to host a workshop, and here that coaches and students across the world register for workshops and other events. This website is the official and promotional face of codebar, crafted to say something specific to every visitor. It is a public space and face that is constructed by the organisers, as was made clear when I interviewed Kayla* about her experiences.

Kayla was the only organiser I interviewed individually (other organisers were interviewed as a group) and, perhaps because the call did not have the conversational, "brainstorming" atmosphere of the focus group interview, her description of the role was very clear on the logistics of organising. She was specific about making a distinction between broader, localized "workshop organisers" and more centralised "admin organisers" (who, for the most part, are also workshop organisers for the London chapter of the organisation). She explained how, along with accounting and banking, some of her duties as an admin organiser involved moderating codebar's online presence and allowing access-for instance, "if a new organiser for a particular chapter comes on board, giving them access to the emails, setting up emails, setting up twitter accounts." Kayla also explained her involvement in managing the organisation's blogs (accessed from the website 
homepage), which include posts about conferences, new chapters and the experiences of "people in the codebar community who we think are doing really good things, and we want to showcase them. And also show their journeys into tech... so that they are an inspiration to other people as well.” Kayla's explanation of the way admin organisers do the bureaucratic work of making the voices of codebar participants heard-giving local chapter organisers access to social media channels and highlighting the stories of community-members - highlights a reality of the role that can be traced to the codebar website more generally. Much of the official face of codebar exhibits community voices to craft a narrative of how the organisation operates. Along with the blog, the homepage exhibits a rotating set of student quotes about the appeal of codebar and its positive effects. In this way, the face of codebar is crafted from the voices of many participants moderated into a single projection of the community - which reflects the functional realities of codebar's internal societal structures. Just as bell hooks' description of the transgressive pedagogy relies in the notion that the instructor is setting the model for learning and, if they are doing so transgressively, is characterizing it as democratized and inclusive; so we can see that codebar's organisers' pedagogical practice is to establish and articulate a vision and presence that is inclusive not only in its goals, but also in its very collaborative nature.

During the focus group interview with organisers, it became evident that part of their shared intention was to use participant contributions to craft an environment or "internal society" that presented on a small scale what the broader society should ideally be at large. Chelsea* shared how her prior experiences as a student at codebar led her to become involved in helping manage its learning provision:

“I’ve got to say, if it wasn't for codebar I don't think I will be pursuing this career as a developer, because codebar served in another purpose of, kind of, highlighting the most vibrant and selfless, like, giving dynamic group.... I think that was, that gave 
me the belief that maybe, you know, tech is not the sterile type... even though it could be an illusion, because the reality is there's still the imbalance of diversity within the industry. But when you see the better parts, you can see the future of it. You feel so encouraged, you can keep on going until you break though.”

In many ways, the content of the website highlights the intended values of this micro-society. Web content uses language like “collaborative”, "safe”, “inclusive”, “diverse” and "accessible” to describe both its intension for internal culture and its goals for the broader tech community. Online manuals provide more specific direction about what this safe, inclusive collaboration looks like-both giving direction for how to positively pursue these, and cautioning against counteractive activities that would undermine these goals. Furthermore, as well as specific valuecrafting content, these online manuals discursively construct social systems for the functioning of codebar-particularly in how they position organisers. Here, organiser responsibility is portrayed as responsibility for accountability — violators of the Code of Conduct are subject to organiser censure, and participants are invited to direct concerns about others' violations to organisers and expect action:

"If a participant engages in harassing behaviour the organisers may take any action they deem appropriate. This includes warning the offender or expulsion. If you are being harassed, notice that someone else is being harassed, or have any other concerns, please contact one of the organisers immediately.” (codebar Code of Conduct)

It is clear that (admin) organisers are the "voice" of codebar, yet their authority is one of responsibility and almost-democratic representation. The way they craft descriptions of codebar for public projection is by combining and moderating participant voices, by practicing empathy (often informed by their past experiences) for those they serve, and by being explicit in their demands and willingness to hold violators accountable. This 
reality of the role was also reflected in how participants spoke about codebar. When asked about what could be improved at codebar, coach Shaun* made clear that he viewed organisers as central, responsible representatives of the community, saying:

"I think codebar could definitely think about what it's teaching the students. I think they should (hesitates) perhaps engage with the community to get some new tutorials written.”

When Shaun says "codebar" and "they", he is referring to the central organising body (he refers earlier to organisers' efforts) but he places distance between the people he knows organise and any sense of critique, clearly unwilling to place the burden of responsibility on their shoulders and instead choosing to attribute it to the organisation as a nebulous whole. In this way, "codebar" and "the organisers" become interchangeable. Yet, Shaun's idea for active improvement is in "engaging the community"-an acknowledgement of the ways codebar organisers moderate and utilise the broader collective of participants. The conclusion is that codebar's reality is a combination of participant input - engaged, moderated, curated and protected by the organisers. If we consider codebar as a possible manifestation of hooks' transgressive pedagogy, in which the role of instructor is both having authority over the establishment of the learning model, and distributing that authority, it can be argued that codebar's particular manifestation of this role comes in the form of a type of collaborative authority.

Collaborative authority is exemplified in the relations between organisers themselves, demonstrated during the group interview. The use of focus group interviews aims to "capitalize on research participant's communication” (Kitzinger 1995, 299) and so they frequently play out in ways that involve a process of participants pursuing consensus, sometimes through routes of contention, connection or persuasion. The way that the group of organisers pursued consensus was striking and remarkably different to other groups, in which this can take the form of heated debate followed 
by someone being convinced or being compelled to back down. In this case, organisers pursued consensus through a "yes and" approach similar to what has been used in improvisational theatre and adapted for other contexts like workplace mediation (Leonard and Yorton 2015) - the speaker acknowledging the point made (“adding to Chelsea's point about...") and adding a further detail or a different perspective. It is clear that the relational context of organiser work at codebar is one of collaborative respect and nonhierarchical shared and individual value. Long-serving organiser, Katherine*, explained how their organising team was intentionally crafted to make such respect possible, because of the necessity to trust co-organisers to work proactively with the ad hoc nature of the voluntary role:

"A lot of times people will be like, 'Oh this person's coming a lot and they really want to help out,' and I know them and I've talked to them a few times, and I say, 'You know what, they're great, but they will not be good for codebar organisers,' because you have to be extremely a self-starter and you have to be extremely proactive. So, the way it works - I don't know if this is like a trade secret (laughs), but basically we will get an email from someone and then whoever e-mails back first... something comes in that we need to deal with, and basically, whoever has the capacity at that point in time, whoever gets it first will deal with it.”

The collaborative authority practiced by codebar organisers, ressembling the distribution of authority promoted by hooks' model, necessitates empowerment of nonorganisers-particularly students. In the codebar context, this takes two forms. First, it requires the creation of an atmosphere that assumes and protects the humanity and value of the student participants (as we will see in the organisers' protection of eligibility criteria and Code of Conduct). And second, it requires that students are made active "subjects" rather than passive "objects" of their own education (as we will see in how organisers direct coaching). 
Central to the goals of codebar- " to enable underrepresented people to learn programming in a safe and collaborative environment and expand their career opportunities"-is serving underrepresented students. Perhaps most vital to the goal is the regulation of that very audience. When visiting the codebar website to register for a workshop as a first-time student, clicking on the desired event will take users to a sign-up page where there is direction to read the Code of Conduct, a description of the groups the workshops aim to serve (with a link to a more detailed description of the eligibility criteria), and a call-to-action that invites the user to click "I understand and meet the eligibility criteria. Sign me up as a student.” Despite this direct call for understanding and pursuit of clarity, codebar organisers still reported having trouble with non-eligible people signing up. Kayla*, when asked in the individual interview about the challenges of being an organiser, was definitive, not hesitating before responding:

"It's the emotional labour. Dealing with abuse, quite often.... Because we do have our eligibility criteria, we tend to get a few people not so happy that we do that. They try to tell us that we are discriminating. I think it's the thing for me that takes the biggest toll because you do get emails from people saying—big rants about what we're doing is wrong, that it’s unfair."

The group interview also explored some of the challenges of regulating eligibility, with Katherine* lamenting that there are frequent attempts by ineligible students to enroll, despite the fact that "it is on the front page of codebar's website, so... I don't know how to make this any more explicit, right, but we should, because obviously it's not explicit enough." Certainly, codebar organisers are experiencing some of the inherent emotional difficulties of being enactors of trangressive pedagogy, as bell hooks claims should be expected. It is clear, after all, that hooks does not see the value of trangressive pedagogy as it being safe, 
comfortable and enjoyable, but as it being liberating and transformative - creating change that can be challenging and unnerving. The discomfort resulting from organisers' work is caused by the fact it radically challenges existing social norms and constructions of power. Ensuring codebar is serving its intended audience is vital to its efforts, as the organisers explained when they discussed how failing to do so would be a betrayal of the sponsors and volunteer coaches supporting the organisation specifically because of its cause. The way that their process for ensuring eligibility is crafted is a vital first stage in creating a pedagogy to serve the intended students.

"I tend to think of codebar as making up for a lot of the extra barriers that certain groups face trying to get into the tech world, because basically I recognise that I haven't really faced them. So, kind of tip the scale in another way," explained Robert*, who explored how his own identity as a white man made him different from those the organisation aims to serve. He and the other organisers explained that they worked mainly on an "honour system”, emailing people whose names may suggest they are not eligible to be students and inviting them to read the eligibility criteria and confirm if it applies to them, but being careful not to ask people to defend or "confess" the aspects of their identity that make them eligible. "My gut instinct generally, if someone says, 'Oh no, I face all these barriers,' is to believe them, you know,' Robert continued. This trust and belief is vital to the inclusiveness of codebar's program. It ensures that the students do not have to defend or explain their experiences as marginalised, removing the burden of consciousness-raising from the shoulders of the marginalised. This, according to bell hooks, is vital to effective collaboration in education, as she suggests in exploring how multi-ethnic feminist scholarly collaboration is more successful when black women do not have to educate their white peers about race and disadvantage. For codebar organisers to effectively do their intended work in leveling the playing field for prospective programmers of particular ethnic, gender or sexual identity - the scale-tipping Robert referred to-the organisation must both 
provide opportunity to "make up for" what marginalised people must overcome, and minimise the extra burdens they carry in the education process. The registration and eligibility system is one way codebar works to do this - although not without a burden on an organiser team, some of whom are of marginalised identity themselves and may have to perform emotional labour beyond their voluntary involvement with codebar, as they defend their existence in the full-time tech workplace (Guy and Newman 2004).

Certainly, the vulnerability that hooks identifies as an unavoidable part of being a transgressive instructor is a key aspect of the role that codebar organisers play. It is, in many ways, a bi-product of the elimination of distance in the transgressive model. Their defense of students' rights to particular opportunities (a recognition of humanity in itself) can be seen to undermine the organiser's comfort, just as hooks explores the sense of insecurity felt by an instructor doing something that is apparently as simple as physically moving from behind their desks into the ranks of the students (and, thus, opening themselves up to more possibility for disagreement, disillusionment and questioning through establishing themselves as equal in humanity to traditionallyaccepted “inferiors”).

\section{Organisers Empowering Participants}

While organisers designed the registration and eligibility process to enable silence, with marginalised people not required to explain their marginalisation, they also designed it to empower students to articulate their learning needs and expectations. During registration for a workshop, students are invited to note what they hope to learn with a drop-down menu. When they arrive at the workshop, organisers invite students to confirm or change this selection when they sign in. That students get to select their own curriculum is a key aspect of the codebar approach, and it allows for variety in learning and teaching. During observation, we saw many students choose to follow a 
codebar-provided tutorial in the workshop, while others brought external activities or small projects they wanted help with (Danielle, as a participant-observer, brought a small self-designed JavaScript project to complete with her coach). For student, Jenna*, selection of what to learn was based on her aim to apply to a coding bootcamp to kickstart her career. She explained in an individual interview:

“I’m probably following a slightly different path than if I had just turned up at codebar, I think, because you have to reach a certain level on FreeCodeCamp and you have to reach a certain level on CodeWars. So, I've basically now done that, and then now the next stage is sort of building a website... whereas I probably would have got on earlier to building the website, but I wanted to see if I could actually achieve the pre-requisites.”

The organisers stressed that this curricular flexibility was at the heart of the codebar model, even showing some hesitation to identify a single "codebar approach to education” because of the individuality of learning and coaching needs. Katherine* explained:

“...the format, it's extremely free-up to interpretation by the coaches and the students. Because there isn't a set curriculum, there isn't a specific language we teach, and our teachers have such varied skills. It really depends on you and your coach on how you want to do it and what you make of it, basically... you can basically decide yourself how you learn best or how you want to interact with your coach, but it's very, very freestyle, I would say.”

Clearly, this is a far cry from the "banking" education model, a model that assumes the authority of the teacher and dismisses the agency of the student to select and guide learning. In the codebar model, students have the initial and vital role of setting the curricular agenda for their entire learning experience. Organisers use this to pair students with capable coaches, and students 
assume the role of learning-definer. This is particularly valuable for students of marginalised identities, because mainstream white/ straight/cis/male narratives about vocal women or ethnic, gender or sexual minorities is that they are "demanding"-a classic example of which is the trope of the "angry black woman" which, bell hooks explains, has allowed white feminists to silence racial critique through dismissing women of color as "too angry." (hooks 1994, 103) Characterising certain groups of people in this emotional way is how holders and systems of power have rejected legitimate demands and needs. By contrast, codebar organisers valuedemands from students, inviting them to articulate their wants and needs in the learning process. Students are established as the "subject" of the educational experience-acting and enacting it-rather than an "object” that passively receives instruction (Freire 1970, 36).

Empowerment of the student does not only happen at the stage of curriculum selection, however. It is engrained in how organisers encourage volunteer coaches (all professional developers, often without much training experience) to teach. When new coaches enter a workshop for the first time, they are greeted by organisers who explain the model to them, ask them about what they hope to achieve in the workshop, and encourage a positive attitude towards questioning and exploration. As a result, students appreciate the "patience" granted to them by coaches, who hear and address their questions even, as Jenna jokingly expressed, "though you're literally going through what to them is like, I don't know, the ABCs.” Questioning, trying things out, and even failing are given a great deal of value in the codebar model. The online organiser-written Coach Guide encourages coaches to "Explain that there are no dumb questions... Let them [the students] stumble. We learn by making mistakes, getting frustrated and working through problems in our own way. Be supportive, but let them explore.” It gives some more direct guidance on how to do this, including letting students try to answer their own (or the tutorial's) questions themselves, and not taking over the keyboard to demonstrate. The coaches, in the 
individual interviews, also explained how questioning was a valuable tool and central to the codebar approach. Shaun explained how, in contrast to other, more traditional classroomstyle coaching he has done, codebar produced better learning and coaching because of one-on-one questioning:

"At codebar, I could see there were things that the student I worked with knew at the end of the lesson.... They're then asking questions that they wouldn't be able to ask if they hadn't really understood it."

By highlighting the value of questioning in online materials and coach and student introductions, organisers not only empower students to learn by trying and even failing. They also place students and coaches on a more equal footing, by establishing coaches as actors who gain as well as give in the learning process. Questions are not only a way for students to receive information, they are also a means for coaches to evaluate learning and determine understanding. The question serves as an opportunity for a coach to "grant" knowledge to the student through a response and also as a way for them to "gain" perspective on the teaching outcomes (a result of which is finding the coaching experience "rewarding"). The act of questioning and answering is a collaborative communication that allows the mutual exchange of benefit between coach and student. This means that, throughout the codebar process, participants are engaging as equal contributors to the community of learning.

In establishing, defining and defending the model for selecting curricula and centering learning around questioning, codebar organisers equalise the standing of coaches and students in the learning model, thereby empowering all to participate in the crafting of the learning process and undermining the "banking" process criticised by Freire and hooks. All participants, both students and coaches, are "subjects" rather than "objects" of the educational experience. 


\section{CONCLUSION}

The work of organising at codebar can be characterised as practicing collaborative authority and participant empowerment to establish an inclusivity-centred learning community. Organisers take on the facilitating role usually assigned to the instructor in hooks' transgressive feminist pedagogy, directing but not completing the technical information-sharing done by coaches. They also operate as a non-hierarchical team, practicing collaborative authority even within the organiser ranks, and experience many of the vulnerabilities associated with the instructor role-particularly within an empowerment-focused learning model. Considered through the theoretical lens of bell hooks' writing on trangressive pedagogy, we can see that codebar is an example of how actors can work to manifest social justiceoriented pedagogies within education efforts to prepare underrepresented people for tech work, treating the nature of learning as equally important to the broader justice it hopes to produce.

Although codebar is not focused on the game sector, but on tech more broadly, this study builds on existing scholarship in game studies in two ways. First, it highlights the importance of attending to pedagogy: to how 'diversity and inclusion' are done on an ongoing basis in educational initiatives; to the terms on which such values are offered and practiced, including in research. Celebrating and advocating these values is not sufficient: they are not merely ends but also means. Although this might seem an obvious point, it is sometimes overlooked in diversity work, including in the games sector, as Fisher, Harvey and Shepherd have shown.

A second, related point is that the effectiveness of such types of interventions is challenging to ascertain. Can we reach any conclusions about how effective codebar is at improving the diversity of the tech sector? This is open to debate. codebar itself, as well as the initiatives reviewed by Fisher, Harvey and 
Shepherd, define their goal in terms of providing access to the industry. The data on this are limited, arguably unconvincing, and it's not entirely clear how such results could be achieved by means of such initiatives alone. Does this make them a vanity project, or a well-intentioned but ultimately ineffective endeavour? We would argue against this conclusion on the basis that such initiatives are nodes in a network of contributions to make digital culture more diverse. In this respect, codebar's accomplishments can be interpreted using Parker, Whitson and Simon's (2017) concept of 'cultural intermediaries': agents which promote and sustain the work of minority players or stakeholders in the game sector, giving them legitimacy and value, and ensuring that their efforts have meaning and consequence. codebar's work gives meaning and value to 'diversity' in digital culture, revealing it to be an ongoing and relational accomplishment rather than only a stable and statistical measure. However, it is worth noting that codebar itself does not necessarily view itself in this way-thus, the inability to measure effectiveness according to this metric of success is arguably a limitation in this research.

Indeed, there remain considerable questions to be asked about feminist pedagogy, codebar and social change in the tech industry. Certainly, more research on outcomes would need to be done to know if codebar is effective in achieving its self-identified goals. We also do not know if codebar London is an outlier-even within the confines of the larger organisation itself. This study does not consider the workings of other codebar chapters, which face different geographical, cultural and industrial realities. To come to broader conclusions about codebar's work, more research would need to be done on these local contexts and on whether the practices of codebar London translate to other chapters in places like Sydney, Cape Town or even Edinburgh. The methodological limitations in the sampling of the study, which relied on participants volunteering for an interview after a public invitation delivered over social media channels, means that the data was weighted towards coach and organiser perspectives-as more of 
these participants volunteered than students did-and so questions remain about how generalisable the conclusions are across the breadth of students being served by codebar. Finally, there continue to be considerable constraints on conclusions that can be made about whether educating underrepresented people for entry into tech employment actually has a significant effect on the sector as a whole. codebar's work focuses on this entry level, rather than advocacy for cultural change within the companies that sponsor it. Added to this is the fact that questions also remain about whether codebar is raising consciousness amongst the marginalised people it educates, as coding-centric workshops rarely involve direct learning of content related to social critique-the "critical consciousness" that is central to Freire's foundational theory. The hope of codebar's efforts is that a critical mass of people of marginalised identities in tech employment will give more voice to the needs of tech minorities, but more longitudinal study is required to determine if these expectations are warranted.

\section{BIBLIOGRAPHY}

Adya, Monica, and Kate M. Kaiser. 2005. "Early Determinants of Women in the IT Workforce: A Model of Girls' Career Choices.” Information Technology \& People18 (3): 230-59. doi:10.1108/ 09593840510615860.

Ahuja, Manju K. 2002. "Women in the Information Technology Profession: A Literature Review, Synthesis and Research Agenda.” European Journal of Information Systems11 (1): 20-34. doi:10.1057/palgrave/ejis/3000417.

Bosa, Deirdre, Anita Balakrishnan, and Todd Haselton. 2017. "Uber Fires More than 20 Workers — Including Some Senior Employees - after Internal Investigation.” CNBC, June 6.

Braun, V. and Clarke, V. 2006. "Using Thematic Analysis in Psychology.” Qualitative Research in Psychology,3 (2): 77-101. 
doi:The publisher's URL is: http://dx.doi.org/10.1191/ 1478088706qp063oa.

Consalvo, Mia. 2008. "Crunched by Passion: Women Game Developers and Workplace Challenges.” Beyond Barbie and Mortal Kombat: New Perspectives on Gender and Gaming. Mit Press Cambridge, MA, 177-91.

Fisher, Stephanie J, and Alison Harvey. 2013. "Intervention for Inclusivity: Gender Politics and Indie Game Development.” Loading... The Journal of the Canadian Game Studies Association7 (11): 25-40.

Freire, Paulo. 1970. Pedagogy of the Oppressed. Bloomsbury Publishing.

Geertz, Clifford. 1973. "Description: Toward and Interpretive Theory of Culture, the Interpretation of Culture.” Retrieved August18 (2007): 113-27.

Google. 2017. “Diversity.” https:/www.google.com/diversity/.

Guy, Mary Ellen, and Meredith A Newman. 2004. "Women’s Jobs, Men's Jobs: Sex Segregation and Emotional Labor.” Public Administration Review64 (3). Wiley Online Library: 289-98.

Harvey, Alison, and Stephanie Fisher. 2013. "Making a Name in Games: Immaterial Labour, Indie Game Design, and Gendered Social Network Markets.” Information, Communication \& Society16 (3). Taylor \& Francis: 362-80.

—. 2015. “'Everyone Can Make Games!': The PostFeminist Context of Women in Digital Game Production.” Feminist Media Studies15 (4). Taylor \& Francis: 576-92.

Harvey, Alison, and Tamara Shepherd. 2017. “When Passion Isn’t Enough: Gender, Affect and Credibility in Digital Games 
Design.” International Journal of Cultural Studies20. SAGE Publications Sage UK: London, England: 492-508.

hooks, bell. 1994. Teaching to Transgress. New York: Routledge.

Johnston, Hank. 1995. "A Methodology for Frame Analysis: From Discourse to Cognitive Schemata." Social Movements and Culture4. University of Minnesota Press Minneapolis: 217-246.

Kitzinger, Jenny. 1995. "Qualitative Research. Introducing Focus Groups.” BMJ: British Medical Journal311 (7000). BMJ Group: 299.

Lagesen, Vivian Anette. 2007. "The Strength of Numbers: Strategies to Include Women into Computer Science.” Social Studies of Science37 (1): 67-92. doi:10.1177/0306312706063788.

Leonard, Kelly, and Tom Yorton. 2015. Yes, and: How Improvisation Reverses" no, But” Thinking and Improves Creativity and Collaboration-Lessons from the Second City. Harper Collins.

Millman, Marcia, and Rosabeth Moss Kanter. 1987. "Introduction to Another Voice." In Feminism and Methodology: Social Science Issues, edited by Sandra G Harding. Bloomington: Indiana University Press.

Nakamura, Lisa. 2013. Cybertypes: Race, Ethnicity, and Identity on the Internet. Routledge.

O’Leary, Zina. 2013. The Essential Guide to Doing Your Research Project. Sage.

Parker, Felan, Jennifer R Whitson, and Bart Simon. 2017. "Megabooth: The Cultural Intermediation of Indie Games." New Media \& Society. SAGE Publications Sage UK: London, England. 
Pelletier, Caroline. 2008. "Gaming in Context: How Young People Construct Their Gendered Identities in Playing and Making Games.” In Beyond Barbie and Mortal Kombat: New Perspectives on Gender and Gaming, edited by Yasmin B. Kafai, Carrie Heeter, Jill Denner, and Jennifer Y. Sun, 145-60. Mit Press Cambridge, MA.

Rubio, Miguel Angel, Rocio Romero-zaliz, Carolina Mañoso, and Angel P. De Madrid. 2015. "Closing the Gender Gap in an Introductory Programming Course.” Computers \& Education82: 409-420.

Scott, Allison, Freada Kapor Klein, and Uriridiakoghene Onovakpuri. 2017. “The 2017 Tech Leavers Study.”

Shrewsbury, Carolyn M. 1993. "What Is Feminist Pedagogy?” Women's Studies Quarterly, no. 3: 8-16.

Stack Overflow. 2017. “Developer Survey Results 2017.” https://insights.stackoverflow.com/survey/2017\#overview.

Thompson, Jane. 2000. “Emancipatory Learning.” NIACE Briefing Sheet11.

Zarrett, Nicole R, and Oksana Malanchuk. 2005. "Who’s Computing? Gender and Race Differences in Young Adults' Decisions to Pursue an Information Technology Career.” In Leaks in the Pipeline to Math, Science, and Technology Careers, edited by Janis E. Jacobs and Sandra D. Simpkins, 65-84. San Franscisco: Jossey-Bass. 